\title{
Maintenance and Preservation of Health in Mashaaikh (Old age) according to Unani viewpoint
}

\author{
MI Manuha ${ }^{1}$, MHM Nazeem ${ }^{1}$ \\ ${ }^{1}$ Senior Lecturer, Institute of Indigenous Medicine, \\ University of Colombo, Rajagiriya \\ Sri-Lanka
}

\begin{abstract}
Population aging around the world is increasing dramatically. Also, it is now a big burden on low and middle-income countries. Healthy old age will be a benefit for the person themselves and the country, too. According to Unani concept, if old age is managed in a proper way that can preserve the health of that individual. Unani texts and published journal articles were considered. Unani describes that the temperament of old age is cold and dry in nature and therefore the regime suitable for old age people renders the body warm and moist. A night of sufficient sleep in a pleasantly aroma odoured room, massage with oil at a moderate level, and then a gentle exercise like walking are beneficial to keep healthy old age. The flow of urine continuously assisted by diluents and also the residues should be out of the stomach by the way of bowels without constipation. A warm bath generally benefits for old age.
\end{abstract}

Key words: Old Age, Regime, Temperament, Exercise.

\section{INTRODUCTION}

Old age denotes to the age nearing or surpassing the life expectancy of human beings, and the person is at the end of the human life cycle. The pace of population ageing around the world is increasing dramatically. The shift in distribution of a country's population towards older ages, known as population ageing, started in high-income countries. It is now low- and middle-income countries are also, experiencing the greatest change [1].

At the biological level, ageing results from the impact of the accumulation of a wide variety of molecular and cellular damage over time. All cells experience changes with aging. They become larger and are less able to divide and multiply. Among other changes, there is an increase in pigments and fatty substances inside the cell (lipids). Many cells lose their ability to function, or they begin to function abnormally. As aging continues, waste products build up in tissues. A fatty brown pigment called lipofuscin collects in many tissues, as do other fatty substances. Connective tissue become stiffer and this makes the organs, blood vessels, and airways more rigid. Cell membranes change, so many tissues have more trouble getting oxygen and nutrients, and removing carbon dioxide and other wastes [1-2].

Beyond the biological changes, ageing is also associated with other life transitions such as retirement, relocation to more appropriate housing, and the death of friends and partners. In developing a public-health response to ageing, it is important not just to consider approaches that ameliorate the losses associated with older age, but also those that may reinforce recovery, adaptation and psychosocial growth [1].

A longer life brings opportunities, not only for older people and their families, but also for societies, as a whole. Older people may contribute in many ways to their families and communities. Yet, the extent of these opportunities and contributions depends heavily on one factor, that is their individual health. If people can experience these extra years of life in good health and if they live in a supportive environment, their ability to do the things and they value will be little different from that of a younger person.

Unani medicine explained about how to keep a healthy life in old age and how to plan the lifestyle changes for the benefit of old age, extensively. Ancient physicians from Hippocrates to Avicenna mentioned what, when and how the food and other lifestyle changes, regimen to be employed to minimize or avoid the physical and mental agony for the elders. Objective is to identified the 
methods how Unani system of medicine explained and guided the preplan activities to retain elders healthy and prevent diseases in their old age of life.

\section{METHODOLOGY}

Search of old age-related information collected from the Unani text and articles were collected from published journal. Online electronic databases Google scholar was used search up to August 2020 in English publications. The following search terms were used to filter the data. As search terms old age, Mashaaikh, Sin e Shaikhookhat were used to filter the articles and summarized. Omitted the articles which were provided repeatedly the same information.

\section{RESULTS AND DISCUSSION}

\subsection{Temperament of Human body in the aged}

Each and every organism and the matter in the world as a whole are furnished with a unique temperament according to their properties and functions of life depend. Hence, the temperament of human body is determined by body humors (body fluids). According to Unani concept the temperament of old age is described as cold and dry in nature and the proportion of body humors in them is considered much different from those of children or other stages of human life.

Unani System of Medicine categorized the human life into four stages viz; Sin e Namu is from birth to the age up to 30 years, Sin $e$ Shabab is from the age of 30 up to 40 years of age, Sin e Kahoolat is from the age of 40 up to 60 years and Sin e Shaikhookhat is above 60 years of age. The group of Sin e Shaikhookhat (old age), is the period in which there is diminished quantity of Ratoobat e ghareeziya (normal fluids of the body). Ratoobat e ghareeziya plays a key role in maintaining equilibrium of hararat $e$ ghareeziya (innate heat of the body). When quantity and quality of ratoobat e ghareeziya changes, it directly affects hararat $e$ ghareeziya and thus difficult to preserve the continuation of normal body metabolism. Excessive reduction (tahleel) in hararat $e$ ghareeziya affects in two ways i.e. diminished hararat e ghareeziya causes change in huzoome arba', which leads to abnormal humours or rutoobat. This lead the domination of ratoobat e ghareeba bala (abnormal metabolic products) in the blood. That weakens the tabiyat (power which control the homeostasis / internal environment of the body) and slows down the bodily function. In this period deterioration in the powers and faculties of the body is noticeable. Abnormal humors (ghair tabaye ratoobat), changes temperament (mizaj) which enhances ageing. This diminished quantity of ratoobat e ghareeziya and hararat $e$ ghareeziya lead to altered temperament in elderly; hence mizaj becomes baarid yabis (cold and dry) [3]. Due to this, in this period deterioration in the powers and faculties of the body is noticeable. It is also asserted that the temperament in aged people is much easily altered by extrinsic and intrinsic influences. Consequently, the homeostasis (Tabi'at) of the elderly is also change easily [4].

\subsection{Maintenance and preservation of health in the aged}

The temperament of old age is more towards the cold and dry and therefore the health preservation for old persons briefly consists of moistening and warming measures.

\subsubsection{Food and Drink for the aged}

Recommended time and diet for the aged

Digestion is weak in old age and therefore the meals should be served in small quantities and frequent interval and thus two to three times a day will be appropriate. In order to specify diet schedule, the day and night are divided in to equal hours. At the third hour of the day time, can serve well-baked bread with honey and at the seventh hour, after a bath a softening food is advisable. Diet should not be given before bathing as it may result in producing obstruction in the vessels [5]. Light and easily digestible food is given in the evening [3]. At bed time commendable nutrient may be allowed [6]. Some heavy foods such as dried meat, salted fish, brinjal or cucumber, watermelon or spicy dish or pickle should be given with appropriate correctives. Muslehat are known as correctives in Unani, which are potential to minimize some undesirable effects in digestion [7].

Milk should be given in old age only if it can digestible properly and not produce any ill effects to the stomach or GIT. According to Unani Medicine, goat milk is best in old age because it is easily digestible in the stomach [3]. Leafy vegetables and fruits suitable for the old age. Vegetables such as beet and celery are good for persons with arthritis tendency and leek serve with olive oil and tasty aromatics help to improve digestion [6].

Beet root and Ma ul Shageer (barley water) are the best diet for old age, because it helps to evacuate abnormal humors the body. Also, this will produce laxation and relieves constipation [3]. Barley is soaked in water for four hours, and boiled (in twenty times water) till the colour of water becomes reddish in colour. This is the method to prepare Ma ul Shageer (Usama \& Quddusi, 2020). Laxation producing fruits such as figs, plums can be given in summer and in winter dried figs cooked in honey water can be given [3]. 
Ginger really a medicine and a good condiment for old-age. The spices like garlic, onion, black pepper and preserved ginger are also more beneficial in old age because they warm the body, aid digestion and does not produce much dryness in their body [3]. Many animal and human based research also revealed that the potential effects of garlic in in many diseases such as correct the anti-lipidemic, anti-atherogenic, anti-rheumatic, cardio-protective etc. Similarly ginger also exhibited many beneficial health effects such as anti-asthmatic, anti-lipidemic, anti-oxidant etc.

Not recommended diet for old age

Heavy foods which produce excess amount of Sauda and therefore heavy foods should be avoided by old people [8]. Foods substances that forms thick blood is known as heavy foods E.g. red meat [9],[10]. Astringent things and condiments should be excluded in the diet or can be taken in less amount for medicinal purposes. Sour diet causes early maturity, so should be avoided $[8]$.

\subsection{Tonics for aged}

Insomnia is a common complaint prevailing in old age and further, lethargy, constipation, and backache etc also included into this. Certain tonics mentioned in Unani system of medicine can effectively manage these complaints. Examples of such effective tonics are Jawarish Jalinoos, Majoon Falasfa, Khamira Gaozaban, Khamira Abresham, Khamira Marwarid, Majoon Azaraqi, Sharbat Faulad etc [8].

\subsection{Drugs and regimes for aged}

Many herbs and even compound preparations which are described by Unani scholars in their old text for the management of aging. A number of single drugs like Aamila (Emblica officinalis), Adrak (Zingiber officinale), Lehsan (Allium sativum), Darcheeni (Cinnamomum zeylanicum), Filfil e siya (Piper longum), Injeer (Ficus carica), Badam (Prunus amygdalus), Aakhrot (Juglans regia), Zafran (Crocus sativus) and many others are mentioned in the Unani text [8].

Scientific studies revealed that, antioxidants have definite role in the prevention of geriatric diseases. Many recent studies scientifically proved that theses herbs and compound preparations possess many biological activities such as antioxidant [11] , immune-modulator [12], cardio- protective [13], hepato- protective [14], reno-protector [15], neuro-protective [16], anticancer [12] etc and therefore, they delay the process of ageing by promote to maintain the humoral balance.

\subsection{Physical Activity for the aged}

Physical activity differs from the physical condition of the individual, disabilities and their habits in regard to exercise. Healthy elderly person should take moderate exercise but elderly suffering from diseases might not strain the affected organs. Person who suffering from cerebral disease, epileptic fits or vertigo should avoid exercises involve bending and drooping of head. They should be content with walking, running, riding and taking exercises in which only to be lower half of the body moves. If lower limbs are affected only upper half of the body to be moved. E.g. resisting exercises, weight lifting and weight throwing. If the abdominal organs are affected, the exercises of both upper and lower halves of body are good without cause unnecessary strain to the organs. In diseases of thorax, exercises can be done to lower limbs. If the organs of genito-urinary system is affected, exercise can be suitable to upper part of the body. However, exercise must be avoided in hot and dry diseases and when the matter is immature and likely to putrefy [3]. Exercise not only benefits various disease/ disorders but it also improves the mind and social interaction as well it reduces insomnia and constipation in elderly patients

\subsection{Sleep for the aged}

Long hours of sleep, more rest than ordinarily by adult is required and necessary for old age.

\subsection{Massage for the aged}

Massage should be of moderate type and weak and painful parts should not be massaged. If massage is repeated on the same day, in between massage the parts must be rubbed with a piece of coarse cloth or bare hands. This would strengthen the vitality of massaged organ and prevent relapses [3].

\subsection{Evacuation of waste for the aged}

Degenerative diseases are very common in old age. Therefore, Unani physicians paid more attention to prevent constipation, as constipation is considered as mother diseases of all degenerative diseases. As first step, the diet should be modified by the Unani 
physician. The soups are prescribed for this purpose: Game birds boiled with water and salt and then flavoured with condiments and with oil; Polypody cooked with chicken soup or beet soup or cabbage soups are also useful [3].

Substance of food which have laxative action, useful for elderly persons. For summer: figs and prunes ; for winter dried figs cooked in water and in honey. These must be having before food to get the laxative action [6].

\subsection{Purgation in old age}

If the constipation remains for more than two days, decoction of cabbage leaves with barley water should be tried. If constipation remains for several days, bowel can be cleared by oil enema or moderate laxative but not with strong enema, which dehydrate the intestines [3].

\subsection{Removal of obstruction}

Obstructions are very common in old age and pennyroyal (kind of mint variety), capsicum, and pepper will be useful to remove. Onion and garlic are also useful to remove obstruction. However, the diet varied to the organ affected. Parsley is advisable in ureter or urethra is blocked and hyssop, maidenhair, cassia are beneficial in lung obstruction.

\section{CONCLUSION}

Unani describes that the temperament of old age is cold and dry in nature and therefore the regiment suitable for old age people render the body warm and moist. A sufficient sleep in a pleasantly aromatic odoured room, massage with oil in moderate level and then a gentle exercise like walking are beneficial to keep healthy old age. The flow of urine also continuously assisted by diluents and the mucus should be out of the stomach by the way of bowels and urine with no constipation. A warm bath generally benefits for the old age.

\section{REFERENCES}

1. WHO. (2018). Ageing and Health. Retrieved from the website https://www.who.int/news-room/fact-sheets/detail/ageingand-health on 21.08.2020.

2. Aging changes in organs, tissues. (n.d.). Retrieved from the website https://medlineplus.gov/ ency/article/004012.htm\#: :text=All\%20cells\%20experience $\% 20$ changes $\% 20$ with,they $\% 20$ begin $\% 20$ to $\% 20$ function $\% 2$ 0abnormally.on 21.08.2020.

3. Mazhar, H-Shah. (1966). The General Principles of Avicenna's Canon of Medicine. Naveed Clinic, Karachi, Pakistan.

4. Ahmed, S.I. (1980). Introduction to Al Umur al Taba'yah. Temperament in Old age. $1^{\text {st }}$ Edition, Published by Hakim (Mrs) Nuzhat Ishtiaq, A \& U Tibbiya College, New Delhi. p 46

5. Jurjani I, Zakheera Khwarzam Shahi. Urdu trans. by H.H Khan, New Delhi: Aijaz publishing house, 1903, 255 - 257.

6. Gruner, O.C. (1930). A Treatise on the Canon of the Medicine of Avicenna, Incorporating the translation of the first book, LUZAC\&CO, Great Russell Street, London.432 - 436.

7. Rehamn S. (2018). Need of revitalizing Unani system of Medicine. Plant Science in Natural Medicine. 2018. Nov. DOI: $10.4066 / 2591-7897-C 1-003$

8. Zahid. 2016. Tadaabeer e Mashaaikh. Retrieved from the website https://www.nhp.gov.in/tadaabeer-e-mashaaikhgeriatric-care_mtl on 05.10.2020

9. Roohi, Z., Sadiya, N.B and Syeda Anjum, F. (2013). DIETO THERAPY IN UNANI SYSTEM OF MEDICINE. INTERNATIONAL JOURNAL OF PHARMACEUTICAL, CHEMICAL AND BIOLOGICAL SCIENCES. 2013, 3(4), 1035-1039.

10. Usama, A \& Quddusi N. (2020). Importance of Dietary Therapy (Ilaj Bil Ghiza) in Unani System of Medicine. ACTA SCIENTIFIC NUTRITIONAL HEALTH (ISSN:2582-1423) Volume 4 Issue 2 February 2020

11. Jang, H. J., Lee, H. J., Yoon, D. K., Ji, D. S., Kim, J. H., \& Lee, C. H. (2017). Antioxidant and antimicrobial activities of fresh garlic and aged garlic by-products extracted with different solvents. Food science and biotechnology, 27(1), 219225. https://doi.org/10.1007/s10068-017-0246-4

12. Sai Ram M, Neetu D, Yogesh B, et al. Cyto-protective and immunomodulating properties of Amla (Emblica officinalis) on lymphocytes: an in-vitro study. J Ethnopharmacol. 2002;81(1):5-10. doi:10.1016/s0378-8741(01)00421-4

13. Shreesh, O., Mahaveeer, G., Santosh, K., Dharamvir, S.A. (2011). Protective effect of Emblica officinalis (amla) on isoproterenol-induced cardiotoxicity in rats. Toxicology and Industrial Health. 2011 , Oct. https://doi.org/10.1177/0748233711413798.

14. Min-Jie, G., Ning, Z., Ke-Qin, X., et al. (2018). Hepatoprotective effects of garlic against ethanol-induced liver injury: A mini-review. Food and Chemical Toxicology. 2018 (3) p 467-473 
15. Shiju, T. M., Rajesh, N. G., \& Viswanathan, P. (2013). Renoprotective effect of aged garlic extract in streptozotocininduced diabetic rats. Indian journal of pharmacology, 45(1), 18-23. https://doi.org/10.4103/0253-7613.106429

16. Nillert, N., Pannangrong, W., Welbat, J. U., Chaijaroonkhanarak, W., Sripanidkulchai, K., \& Sripanidkulchai, B. (2017). Neuroprotective Effects of Aged Garlic Extract on Cognitive Dysfunction and Neuroinflammation Induced by $\beta$ Amyloid in Rats. Nutrients, 9(1), 24. https://doi.org/10.3390/nu9010024. 